\title{
Supplemental material for "New methods for retrieval of chlorophyll red fluorescence from hyper-spectral satellite instruments: simulations and application to GOME-2 and SCIAMACHY"
}

\author{
J. Joiner ${ }^{1}$, Y. Yoshida ${ }^{2}$, L. Guanter ${ }^{3}$, and E. M. Middleton ${ }^{1}$ \\ ${ }^{1}$ NASA Goddard Space Flight Center, Greenbelt, MD, USA \\ ${ }^{2}$ Science Systems and Applications, Inc., Lanham, MD, USA \\ ${ }^{3}$ Helmholtz Centre, Potsdam, Germany \\ Correspondence to: J. Joiner (joanna.joiner@nasa.gov)
}




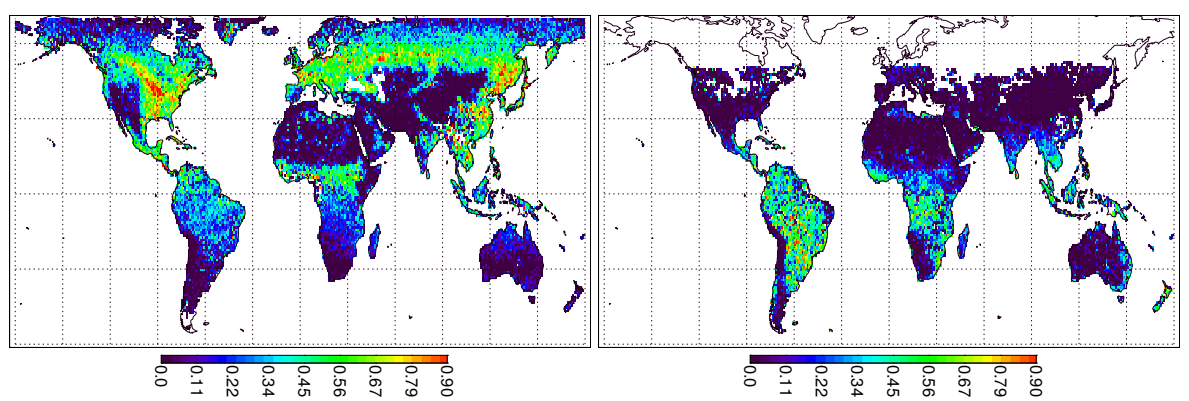

(a) SCIAMACHY retrievals using fitting window $682-686.6 \mathrm{~nm}$

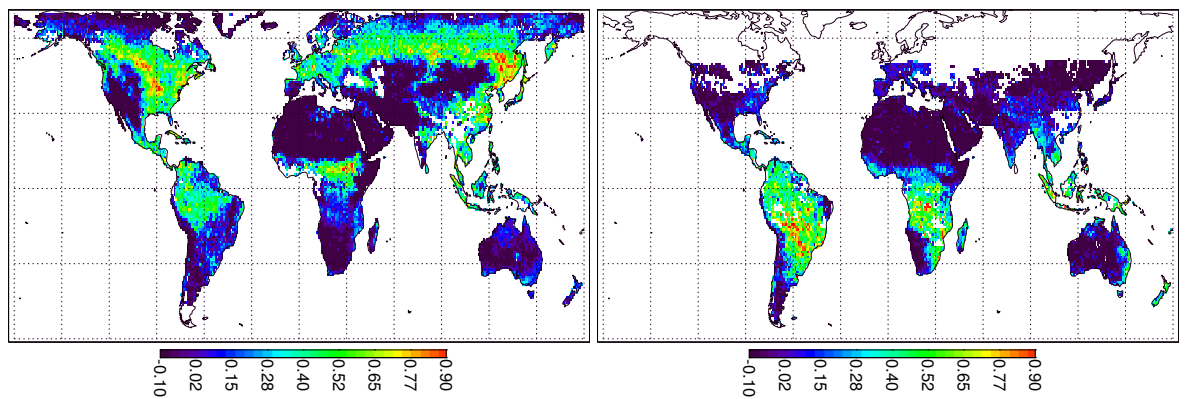

(b) Similar to (a) but using fitting windows in $\mathrm{O}_{2} \gamma$ - and B-bands.

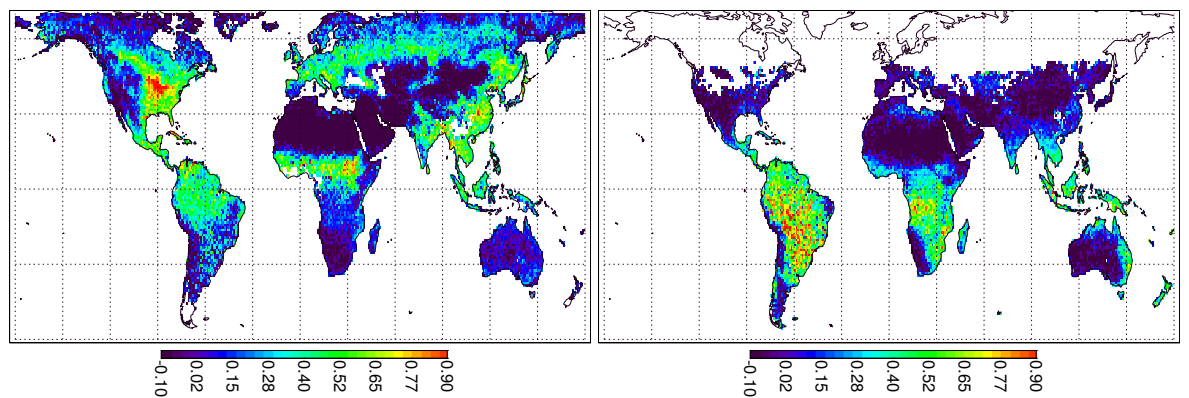

(c) Similar to (b) but using GOME-2.

Figure 1. Global composites of red SIF from SCIAMACHY and GOME-2 binned in $1^{\circ}$ cell boxes with zero-level adjustment for July (left) and December (right) 2007. 


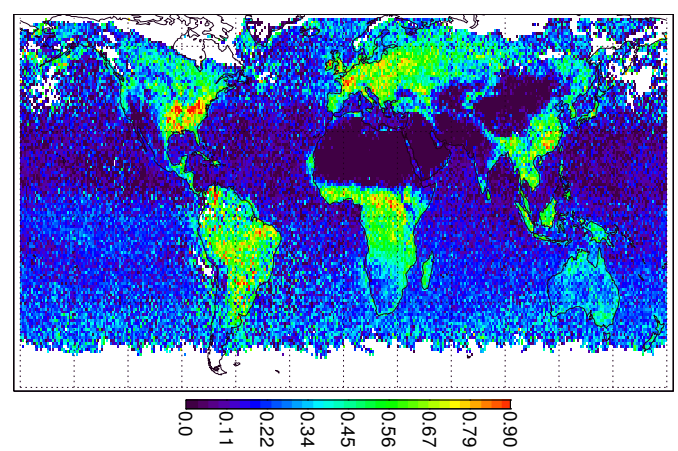

(a) GOME-2 uncorrected $\mathrm{O}_{2}$ band red SIF retrievals.

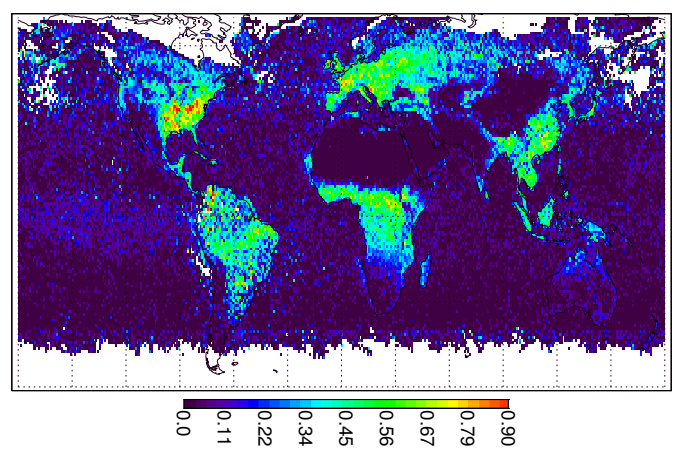

(b) GOME-2 corrected $\mathrm{O}_{2}$ band red SIF retrievals.

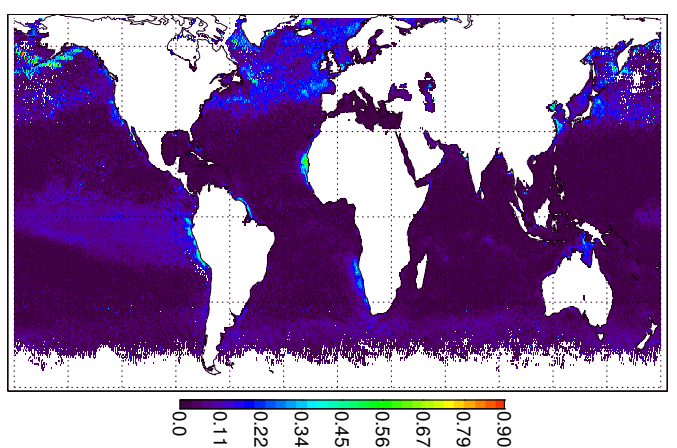

(c) GOME-2 full band ocean FLH retrieval (no correction).

Figure 2. Monthly mean fluorescence from different retrievals with and without corrections as noted in $\mathrm{mW} / \mathrm{m}^{2} / \mathrm{sr} / \mathrm{nm}$ for May 2007 gridded to spatial resolutions of $0.5^{\circ}$ in (c) and $1^{\circ}$ resolution in (a) and (b). 